\title{
CROSSED EXPERIMENTATIONS OF LOW-ALTITUDE SURVEYS FOR THE DETECTION OF BURIED STRUCTURES
}

\author{
Alexandre Van Dongen ${ }^{1}$, Peter Eeckhout ${ }^{2}$, David Lo Buglio ${ }^{1}$ \\ ${ }^{1}$ Laboratoire AlICe, Faculté d'Architecture, Université libre de Bruxelles, Belgium, avdongen@ulb.be, david.lo.buglio@ulb.be \\ ${ }^{2}$ CReA-Patrimoine, Faculté de Philosophie et Sciences sociales, Université libre de Bruxelles, Belgium, peter.eeckhout@ulb.be
}

KEY WORDS: Digital Heritage, Photogrammetry, Thermal Survey, Aerial-GPR, Buried Structures, Large-scale Survey

\begin{abstract}
:
Drones are becoming essential in the field of heritage surveying, especially for large-scale archaeological site. The precision offered by the new survey tools (UAVs, sensors, processing software, etc.) should make it possible to obtain enough information to complete the plan of a site on an urban scale.

This paper shows the use of two types of sensors embedded simultaneously on a UAV with the aim of highlighting information that is often difficult to detect on the ground. By crossing RGB and thermal data, certain built-up limits seem to appear. Thanks to this new information, hypotheses of the urban structure are proposed. In other words, the aim is to bring out circulation hypotheses within a large complex archaeological site. Unlike the field of architectural survey where thermography is widely used, for example, to identify certain building pathologies, in archeology this technique does not seem to be part of the traditional survey pipeline and even less on large-scale sites. The possibility of using a third type of sensor is also sketched. The aerial-GPR would in fact make it possible to confirm the presence of a buried structure without having to go through systematic excavation and could provide a threedimensional image of the ruins.
\end{abstract}

\section{INTRODUCTION}

Nowadays, there are many tools from several disciplinary fields (Jockey, 2013) (engineering, computer science, architecture, archaeology, etc.) for carrying out surveys of built heritage. Each of these tools provides its own set of data and offers the possibility to accurate the knowledge of surveyed building.

The democratization and developments in the field of drone have, in recent years, made this technology essential in archaeology (Campana, 2017) and more generally in the survey of built heritage. Drones are quickly deployed on the site; several types of sensors can be embarked simultaneously, and they allow directly georeferenced data acquisition. It is therefore a tool particularly suitable for surveying large-scale structures.

These technological evolutions in the field of heritage surveying stimulate the ambition of an accuracy that can reach the scale of $1 / 1$ and thus reproduce exactly the reality (Vergnieux, 2009), at a time corresponding to the acquisition, in a virtual space. It is important to specify that the term 'survey' implies a sequence of operations which starts with the acquisition of data and ends with the representation of the object studied (De Luca, 2006; PierrotDeseilligny, De Luca and Remondino, 2011).

In archaeology, especially when we are dealing with a largescale, partially altered and buried case study, it's sometimes difficult to obtain an exhaustive plan of the last occupation of a site. Besides the state of deterioration of buildings, parts of constructions are very often buried under a relative layer of soil or sand and it's even more complicated to completely excavate it. In addition, an archaeological site contains several superimposed layers of occupation. Without being able to read all these temporal tangles, having a detailed understanding of the most recent stratum could be already an issue.
This paper presents two plus one crossed experimentations of aerial surveys: photogrammetry and thermal survey, plus ground penetrated radar (GPR). The different datasets are treated independently, and the results are crossed in order to bring out information making certain built-up boundaries still buried visible, as well as any links between some monumental parts. It is a question here of showing the contribution of these various tools in the field of the large-scale survey but also the interest of cross-referencing the data, or more exactly the resulting information.

The case study is the archaeological site of Pachacamac (FIG.1), South of Lima, Peru. It is a monumental sanctuary erected by four successive civilizations (Lima, Wari, Ychsma, Inca) with a permanent occupation of 10 centuries until the arrival of the conquistadors (Eeckhout, 1999, 2013; Makowski and Vallenas, 2015).

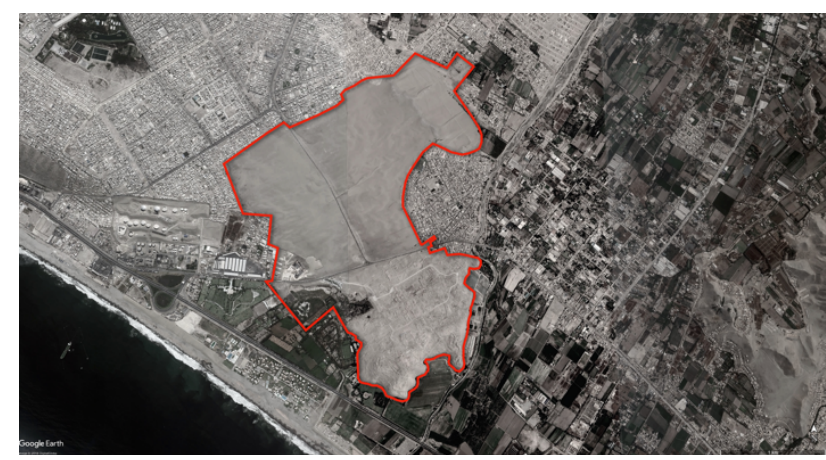

Figure 1. Footprint of the archaeological site of Pachacamac (C) Google Maps 2018)

The physical (materials used vs desert environment) and morphological characteristics (entanglement of buildings) of 
Pachacamac make it difficult to read the built boundaries (FIG.2). Numerous questions remain about the circulation within the sanctuary and about the links between the different buildings.

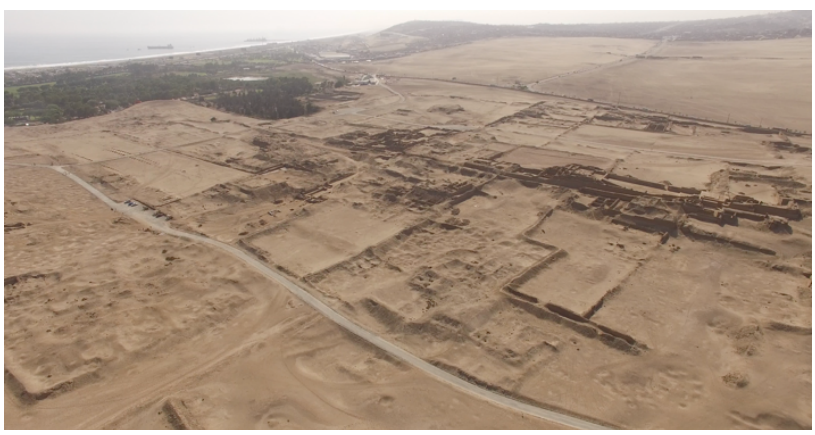

Figure 2. Aerial view of the site (C A. Van Dongen)

The aim is to consolidate and enrich a digital model, which is in fact a hypothesis of restitution of the entire site carried out by conventional topographic survey in order to propose digital 3D restitution of the last occupation. The final model would serve as a base for carrying out different types of analysis (space syntax, visual graph analysis, etc.).

It is also a question of developing new avenues of reflection for the exploitation of massive data in order to increase knowledge of the logics of urban design in a large-scale prehistoric archaeological context. In addition to the automatic analysis methods developed for the study of the morphological properties of buildings (Lo Buglio et al., 2015), the data resulting from the digitization work could also make it possible to analyse and represent the invisible to the eye.

The information contained within the digital models can relate as much to the geometric characterization of surfaces as to the intervisibility links between different buildings, the analysis of the flow of people through a space on an urban scale or even the representation of buried structures.

\section{A QUICK STATE-OF-THE-ART}

As stated above, drones are always improving and becoming more democratic. UAVs manufacturers offer ever more efficient machines both in terms of flight capabilities and sensors (Wierzbicki, 2018; Marín-Buzón, 2021). Ready-to-fly drones now allow simultaneous data acquisition in the visible and thermal (IR) fields. In addition, the ease of use of autonomous mission programming software and the possibility of RTK (Real Time Kinematic) georeferencing provide additional precision. Drones have therefore become a valuable tool for photogrammetric acquisition (Colomina and Molina, 2014).

\subsection{Aerial photogrammetry}

Aerial photogrammetry is not new, it has already shown its usefulness on numerous occasions (Saleri et al., 2013; Sabina et al., 2015; Mozas-Calvache et al., 2012; Abergel et al., 2017). Most of the time, photogrammetric surveys are used for the visualization, documentation, conservation or restoration of built heritage (Elkhrachy, 2018; Carvajal-Ramírez et al., 2019; Bakirman et al., 2020).

Beyond the acquisition phase, data processing tools have also evolved. Whether hardware or software, the entire digitization chain has been automated, perfected and has become much more user-friendly than ten years ago (Feng et al., 2019; Sebar et al. 2021).

\subsection{Thermal survey}

Since the 1970s, aerial thermography has been used in archaeological prospecting (Casana et al., 2017), especially for areas with low vegetation such as fields (crop markers). Since the 1970s, aerial thermography has been used in archaeological prospecting (Casana et al., 2017), especially for areas with low vegetation such as fields (crop markers). But aerial thermography was very expensive at the time. Today it has been democratized and is increasingly used for the detection of structures and archaeological prospecting (Poirier et al., 2013; Thomas, 2018; Hill et al., 2020).

\subsection{Aerial-GPR}

The use of GPR in archaeology is also not new. Several case studies have shown its interest, whether in terms of prospecting or attempting to model buried structures (Neubauer, 2002; Verdonck, 2008; Malfitana et al., 2015; ). GPR is generally implemented as close to the ground as possible, which limits its use in areas with rough terrain. The airborne GPR (UAV) begins to develop (Van Dongen et al., 2018; Wu et al., 2019 ; Edemski et al., 2021) but makes the treatments more complex due to the altitude and therefore the distance between the ground and the antenna.

A few studies also show the benefits of using several of these techniques combined (Piga et al., 2014; Pisz et al., 2020), but without really crossing the data in the same representation. Nevertheless, the stratification of several reading levels could increase the intelligibility of urban or architectural exams of a site.

\section{DEVELOPPED METHODOLOGY}

The survey methodology is first developed at the level of photogrammetric and thermal acquisition. The aerial-GPR approach is then set out in a following subsection.

\subsection{Thermal and photogrammetric surveys}

To facilitate both the survey and the processing phases, the choice of drone for the acquisition campaign turned to a small UAV that can simultaneously shoot RGB and thermal images (Mavic 2 Enterprise Advanced). The RGB sensor is a 1/2 inch 48 Mpx CMOS with a focal length of $24 \mathrm{~mm}$. The thermal images are taken with a $640 \times 512$ px radiometric sensor at $30 \mathrm{~Hz}$ and whose focal length is $9 \mathrm{~mm}$. The drone has a theoretical flight time of 31 minutes without wind.

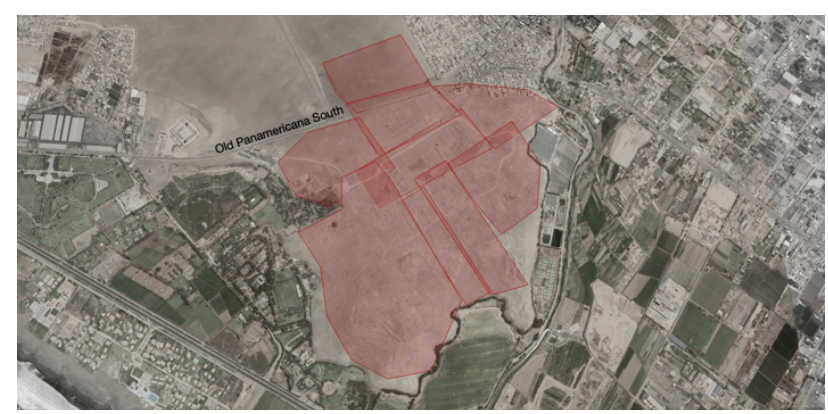

Figure 3. Location of survey areas 100m AGL (C Google Maps 2021) 
The mission planned in September 2021 for the field acquisition was 4 days. The objectives were to survey the entire monumental area of the Pachacamac site (approximately $130 \mathrm{ha}$ ), and part of the desert area located north of the Old Panamericana South Road (18 ha) (FIG.3). The flight altitude for these acquisitions was $100 \mathrm{~m}$ in order to be able to survey a maximum surface in a minimum of time while maintaining sufficient precision. Moreover, the weather was very cloudy with a ceiling at about a hundred meters.

A more precise survey (lower altitude, around $20-25 \mathrm{~m}$ ) of three buildings (B4, B15 and E3) was expected. These are buildings partially excavated during previous campaigns and for which knowledge of the buried structures is sufficient to test and apprehend the reading of the thermal results (FIG.4). Finally, a last zone (Zone D at $40 \mathrm{~m}$ flight altitude) was surveyed. This zone is devoid of significant relief, which makes it possible to understand the influence of relief on the interpretation of thermal images.

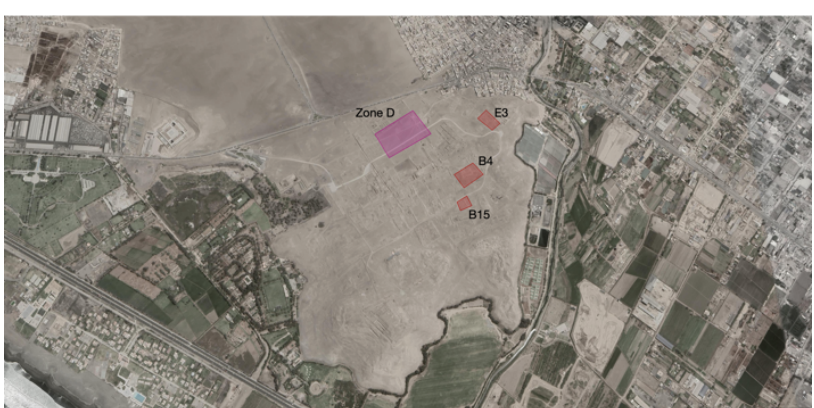

Figure 4. Location of survey areas lower altitudes (C) Google Maps 2021)

Each flight is programmed in such a way as to make the flight $100 \%$ autonomous (FIG.5). The maximum area the drone can cover is calculated based on the battery capacity. However, the theoretical flight time used for the calculation of the acquisition area is largely overestimated because it does not consider the real flight conditions (temperature and wind have a great influence on the flight time). In order to test the drone in field conditions, the first acquisition flights are operated at low altitude above building B15, the size of which allows the use of a single battery for complete acquisition at 20m AGL (Above Ground Level). The entire site was surveyed in several parts depending on the number of batteries available (4).

As mentioned above, the shots are taken simultaneously in RGB and thermal thanks to the dual sensor. However, there is a small latency between the two types of shooting and the focal length is of course not the same. This last point does not have much influence because it is raw data which is then processed separately.

The acquisitions were reproduced at several times of the day. September corresponds to winter in Peru and the temperature differences between day and night are not very high $\left(\Delta \mathrm{T}=\sim 4^{\circ} \mathrm{C}\right)$. The weather conditions are mostly cloudy, but in the middle of the mission two sunnier days warmed the ground.

\subsection{Data processing}

The data processing is carried out with Metashape, both for the thermal part and RGB. Thermal images are lightweight and allow for the highest quality processing up to the extraction of an orthoimage. In parallel, RGB images are also processed.
However, the quality is slightly reduced for DEM (Digital Elevation Model) extraction depending on the size of the images and the processing capabilities of the computer. However, the final DEM extracted from the RGB survey has an accuracy of $1.75 \mathrm{~cm} / \mathrm{px}$. The precision is $14 \mathrm{~cm} / \mathrm{px}$ for the thermal orthoimage at an altitude of $100 \mathrm{~m}$.

The thermal survey is therefore mainly used for thermal orthoimage extraction. It should be noted that while an area may appear to have a lower temperature, it does not mean that a built structure is present underground. It is accepted that the relief influences the temperature of the ground according to the inclination with respect to the sun's rays. It is therefore necessary to be able to interpret these data. The idea is to combine these representations in order to obtain an enriched DEM (with thermal data) superimposed in QGIS (free GIS software). For better readability, the DEM is transformed into contour lines, which makes it possible to increase the understanding of the relief of the ground and the superficial buried structures. The DEM is important for the interpretation of thermal maps. Indeed, the faces of a mound, even a small one, do not always have the same temperature. A face can appear cold when there is no colder material below its surface, the temperature changes with respect to the orientation. On the other hand, a flat area, if there is no change of materials underneath, will present a relatively similar temperature over its entire surface.

Finally, the plans extracted from the original 3D models (made by a classic topographic survey) are compared in order to complete the model with the information extracted from the aerial survey campaign.

\subsection{Aerial-GPR survey}

Concerning the aerial-GPR survey, the experiments are currently focused on building B15. This building has the advantage of having been excavated during several campaigns. The different layers of successive structures are therefore already known, which facilitates the reading and interpretation of the data coming from the GPR. Based on photogrammetry carried out at the end of the last ULB excavation campaign, a reduced model of the building was made.

A negative footprint of the building was $3 \mathrm{D}$ printed to serve as a mold in which clay was placed in order to obtain a model as identical to the building as possible in terms of material. Tests with the model buried in sand at the GPRLouvain laboratory made it possible to set up a survey protocol (FIG.6).
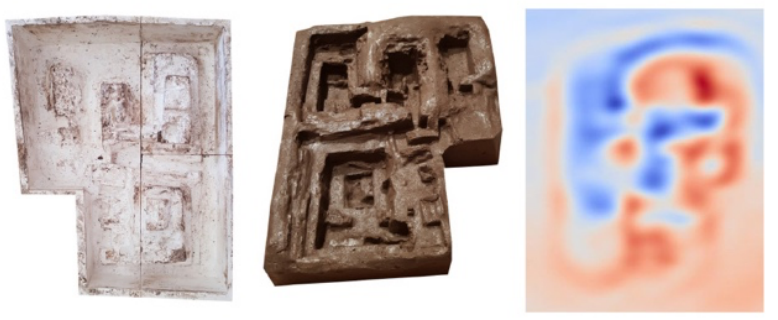

Figure 6. Printed mold (left); Clay model (center); First results: horizontal section (right)

For logistical reasons, the field tests (directly done on the site of Pachacmac) had to be limited to a passage of the GPR $50 \mathrm{~cm}$ above the ground, the radar being placed in the middle of a structure held at arm's length (FIG.7). 


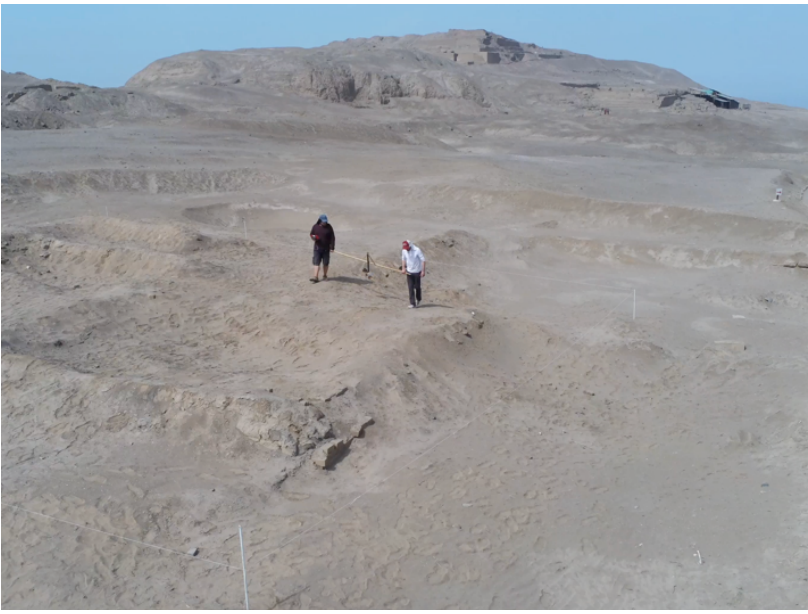

Figure 7. Aerial-GPR test on the B15, Pachacamac

The data is still being processed, but the laboratory tests show the potential for the aerial detection of buried structure.

\section{RESULTS}

Several types of representations can be produced. Each of them makes it possible to visualize information that is difficult to observe directly in the field. Two visualization scales are presented here, one at the scale of the site and the other at the scale of the building.

\subsection{Large-scale}

Data from the monumental zone and the area north of the Old Panamericana were processed in the same Metashape project. First, a complete orthophoto was produced (FIG.8). The constructions are difficult to visualize because the adobe buildings (mudbrick) merge with the sandy environment.

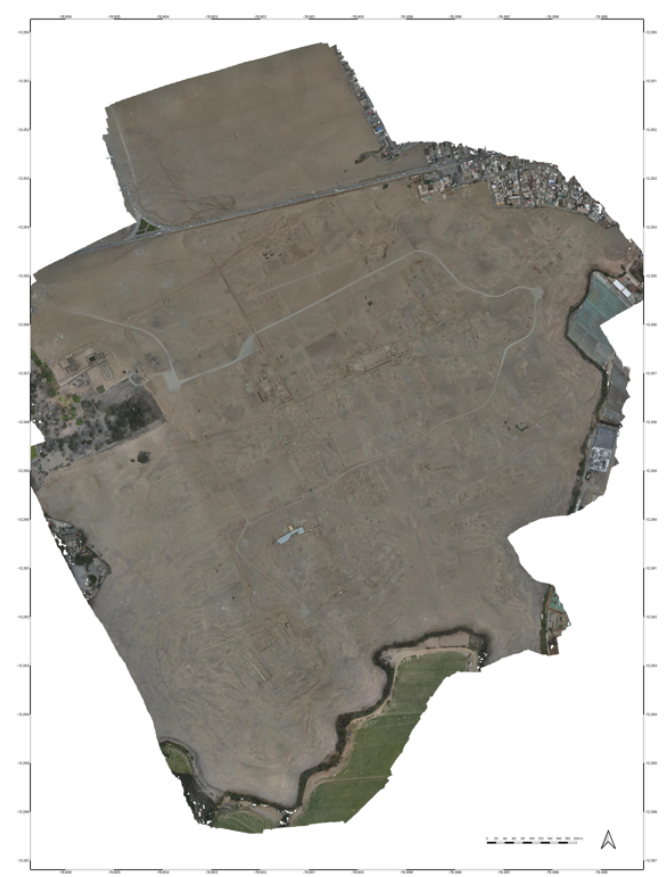

Figure 8. Orthophoto of monumental part and un small part of north aera
The RGB images were also used to generate a relatively precise DEM $(1.75 \mathrm{~cm} / \mathrm{px})$ of the entire site (FIG.9) and to extract the contour lines.

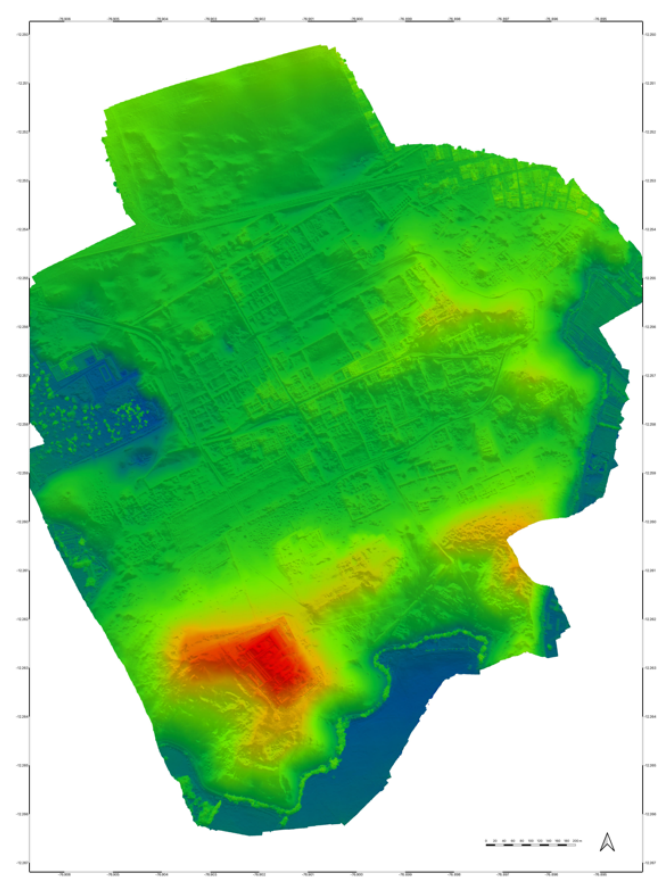

Figure 9. Digital Elevation Model

Thanks to this, the buildings visible or slightly covered with sand appear more clearly and the understanding of the site by the orthophoto is improved (FIG.10). At this stage, the information contained in the orthophoto+DEM offers slight improvements to the original 3D model mainly in terms of the spatial positioning of certain buildings. However, no new structures or walls seem to appear.

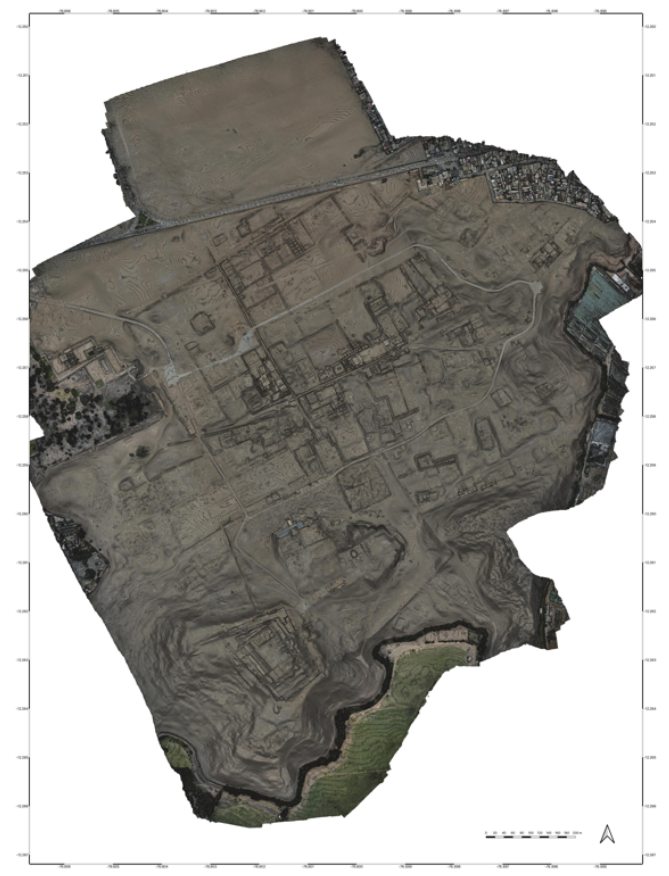

Figure 10. Overlay of orthophoto and contour lines 
The processing of thermal images followed the same workflow as traditional photogrammetry and made it possible to extract a complete thermal orthoimage of the same area (FIG.11). This image, like the two previous ones, is also georeferenced and could therefore be introduced into the same QGIS project. The difficulty here is to distinguish what is really a buried structure or simply a difference in temperature due to the inclination of the ground or a change in the type of soil (e.g. soft ground vs hard ground or stony ground vs sandy ground). Here again the contour lines are an additional clue which accentuate the degree of probability of the location of a built structure.

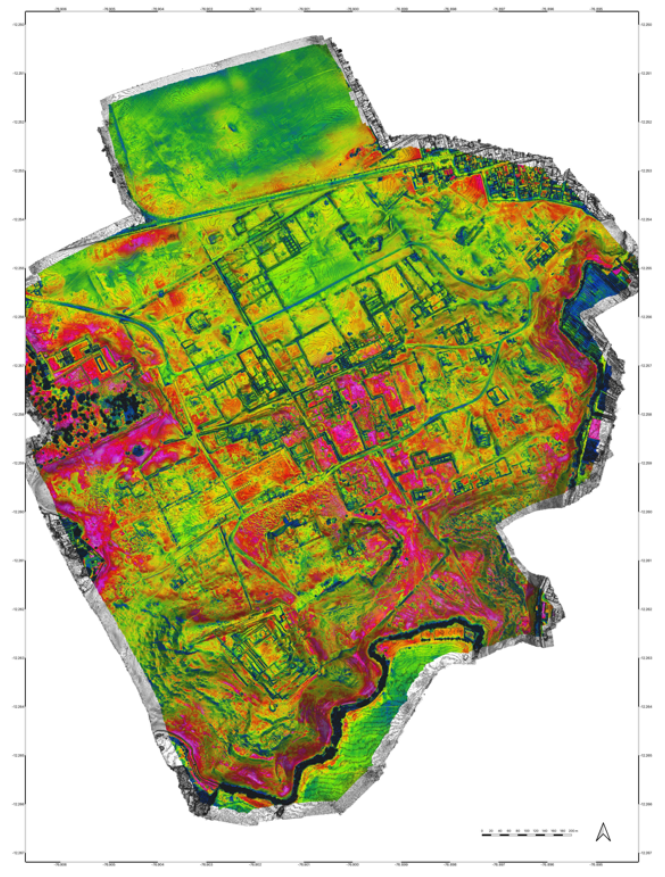

Figure 11. Overlay of orthophoto and contour lines

Moreover, since the acquisition was not carried out in a single flight, the climatic conditions were not the same between the different parts of the zone. The interpretation of the final thermal image must therefore be done carefully and step by step.

Finally, a comparison with the plan from the original 3D model (georeferenced in the same QGIS project) revealed the probable presence of walls that seem to correspond to the general urban framework of the Pachacamac site (FIG.12). Completing the general numerical model allows further studies on the circulation within the site and improves its general understanding.

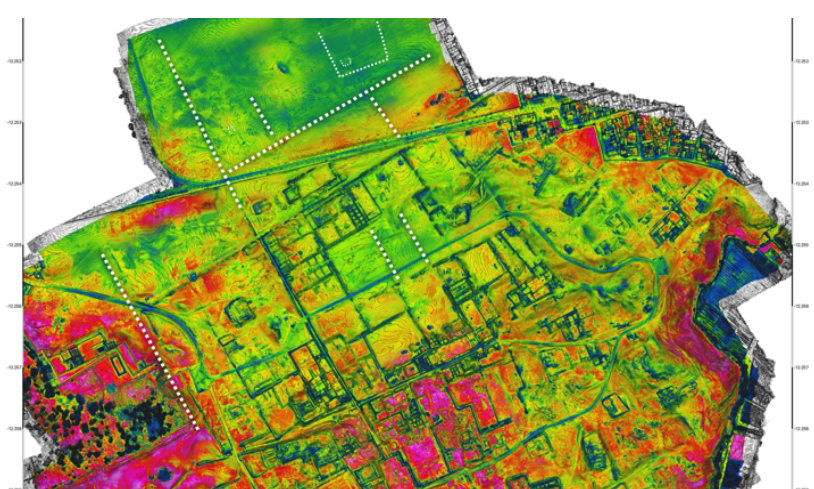

Figure 12. Example of visualization of potential buried structures (white tilled lines)

\subsection{Building-scale}

Before mentioning the experiment carried out on the three different buildings (B4, B15 and E3), zone D is interesting for understanding the reading of the thermal map. Indeed, the Zone $\mathrm{D}$ is a flat area which seems devoid of any structure according to the last plan (FIG.13) as well as on the site.

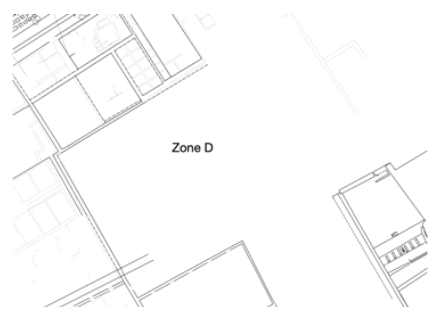

Figure 13. Plan of the zone D (C) Ychsma Project 2018)

By looking only at the photogrammetric data, the orthophotography (Fig.14) shows nothing in particular except for paths taken by current site museum workers and a small irregularity in the middle of the area.

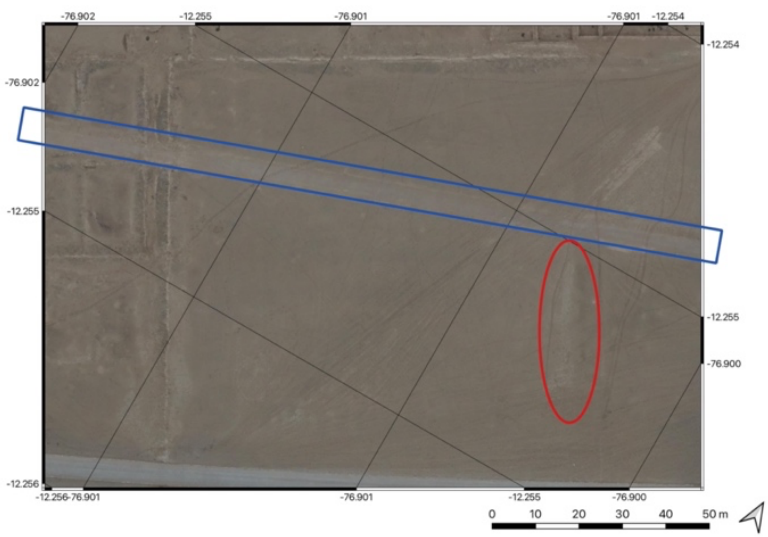

Figure 14. Zone D orthophoto from photogrammetry set with in red a small irregularity and in blue the path of workers.

The DEM (Fig.15) confirms this irregularity by indicating at this point a slight level difference between the western and eastern parts of the area but do not provide any additional information. Usually, the DEM offers the possibility of observing microreliefs which are not perceptible on the orthophotography.

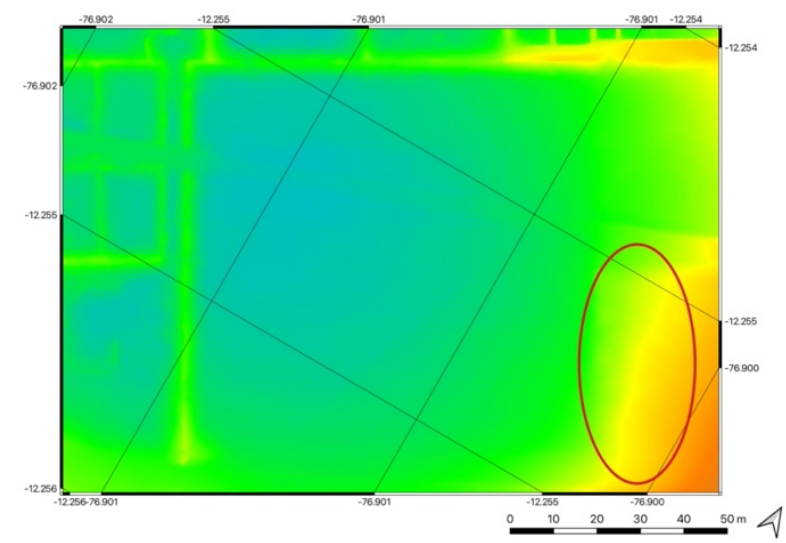

Figure 15. DEM from photogrammetry data set with localization of a slight level difference 
However, the thermographic survey seems to indicate the presence of a small structure on the northwest corner and the existence of a wall at the exact place where the level difference is observed. A colder zone is also detected in the southern part. A GPR survey at this location (to stay in non-invasive prospecting) would be interesting to determine the causes.

The map obtained by crossing the information from thermal and photogrammetric surveys (Fig.16) allows a better reading of structures located just below ground level. Indeed, thanks to the contour lines extracted from the DEM it is easier to judge if the temperature irregularity is due only to the relief (slope) or if it is really the nature of the subsoil which generates a sudden change in temperature.

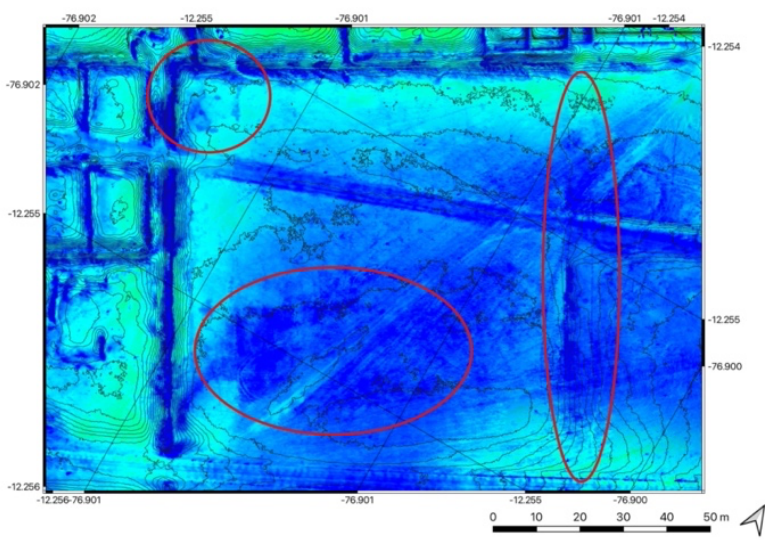

Figure 16. Crossed results of the various surveys of zone D with highlighting of potential buried structures

The results for the three buildings are more complicated to highlight. This seems mainly linked to the quantity of structures present and the overlapping, the interweaving of different construction phases (especially for building B15). Reading the thermal map becomes more complex. On the B15 (FIG.17) results, there are many temperature variations (often small) but difficult to identify as walls. Aerial-GPR data could help here to better understand the thermal results.

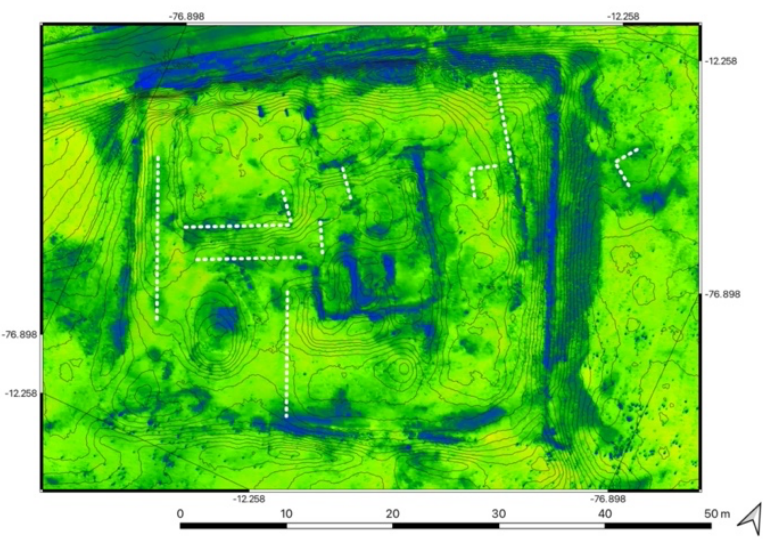

Figure 17. Crossed results of the various surveys of zone B15 with visualization of some first potential buried structures (white tilled lines)

In addition, the areas of previous excavations are very visible, especially in building B4 (FIG.18). Indeed, after the excavations, to keep the ruins in good condition of preservation, the excavated areas are systematically filled in. This leads to a change in the nature of the soil due to the slightest compaction of the soil.

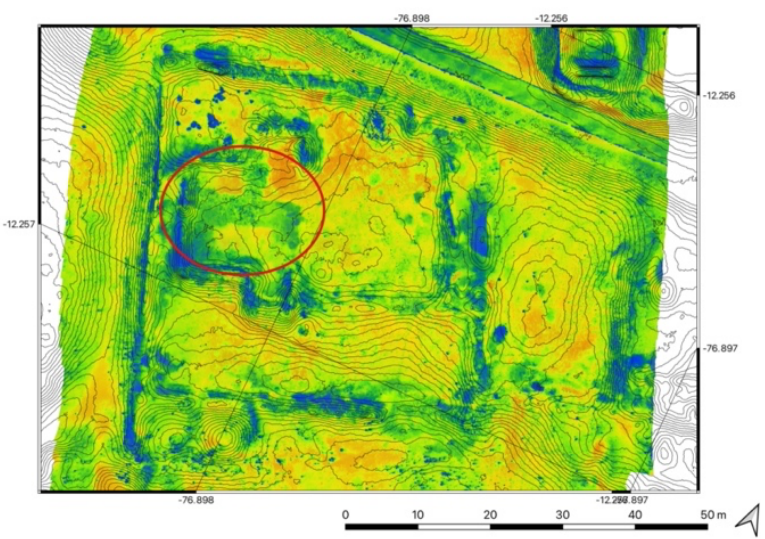

Figure 18. Crossed results of the various surveys of zone B4 with highlighting of previous excavations

The last results are those of building E3 (FIG.19). The thermal image shows the possible presence of structures that seem to extend more easily identifiable walls. These walls are located around the perimeter of the building and appear to form a peripheral corridor. However, given the height of the drone during the acquisition (between 20 and $25 \mathrm{~m}$ ), the resolution of the thermal orthoimages is $3.49 \mathrm{~cm} / \mathrm{px}$. The enclosure walls of buildings are generally thicker (sometimes several meters) than those inside. The accuracy obtained at lower altitude should be sufficient to identify the presence of any structures.

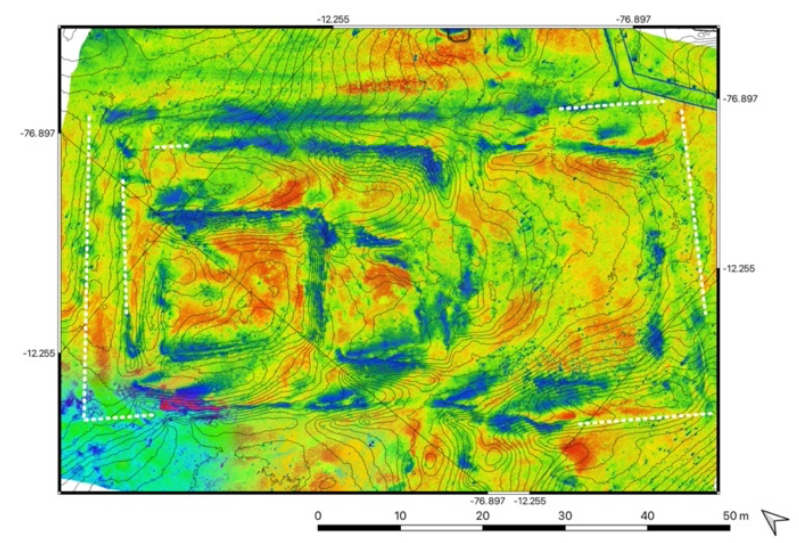

Figure 19. Crossed results of the various surveys of building E3 with potential buried structures (white tilled lines)

\section{CONCLUSIONS}

This paper shows the interest of the multi-sensor survey at the territorial scale in an archaeological context. Each data layer provides additional information. The first results discussed above show the potential of the developed methodology to enrich an existing numerical model (FIG.20). This operational chain (acquisition, analysis, cross-referencing of data) is a way to move forward on the formulation of a spatialized hypothesis of the site to study the planning/circulation logics. 


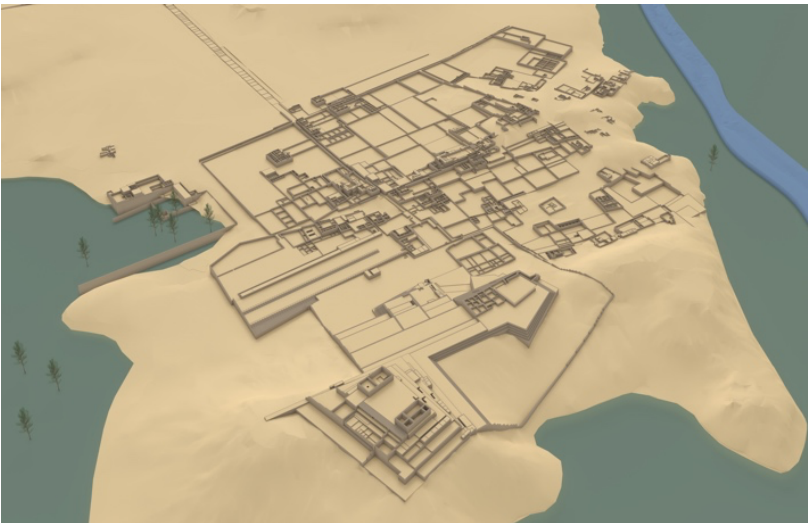

Figure 20. Original digital model from a topographic survey by the Ychsma Project of the Université libre de Bruxelles (ULB).

The building-scale experiments presented here are limited and deserve greater observation and interpretation. For now, only a more in-depth transdisciplinary discussion (archaeologists and architects) has been possible on the scale of the site. It appears that this approach shows an interest in terms of providing new hypotheses for the urban structuring of Pachacamac. All the northern part (desert part) should be surveyed.

It also seems necessary to extend this approach to the different buildings and to combine it with the aerial-GPR survey which could provide more details at deeper levels than the superficial layers recorded by thermography.

Aerial GPR is still exploratory on this type of terrain, but the information it could provide would make it possible to ensure the effective presence of a structure other than by excavation, in a non-invasive manner. The GPR would make it possible to further enrich the interpretations of the thermal maps.

Finally, a finer survey strategy would be to carry out new acquisitions at night, or at nightfall, when the temperature differences between the subsoil and the ground are the greatest.

\section{ACKNOWLEDGEMENTS}

We would like to warmly thank Denise Pozzi-Escot, Director of El Museo de Sitio del Santuario de Pachacamac and all her team for the ease of access and their help and collaboration throughout the mission. We also extend our thanks to Professor Sébastien Lambot of the GPRLouvain (UCLouvain) for the research collaboration at the aerial-GPR level.

\section{REFERENCES}

Abergel, V., Saleri, R., \& Lequay, H., 2017. Vecteurs aériens téléopérés pour l'acquisition de données spatiales d'objets patrimoniaux-retour d'expérience. Revue française de photogrammétrie et de télédétection, (213-214), 73-79.

Bakirman, T., Bayram, B., Akpinar, B., Karabulut, M. F., Bayrak, O. C., Yigitoglu, A., \& Seker, D. Z., 2020. Implementation of ultra-light UAV systems for cultural heritage documentation. Journal of Cultural Heritage, 44, 174-184.

Campana, S., 2017. Drones in archaeology. State-of-the-art and future perspectives. Archaeological Prospection, 24(4), 275296.
Carvajal-Ramírez, F., Navarro-Ortega, A. D., Agüera-Vega, F., Martínez-Carricondo, P., \& Mancini, F., 2019. Virtual reconstruction of damaged archaeological sites based on Unmanned Aerial Vehicle Photogrammetry and 3D modelling. Study case of a southeastern Iberia production area in the Bronze Age. Measurement, 136, 225-236.

Casana, J., Wiewel, A., Cool, A., Hill, A. C., Fisher, K. D., \& Laugier, E. J., 2017. Archaeological aerial thermography in theory and practice. Advances in Archaeological Practice, 5(4), 310-327.

Colomina, I., \& Molina, P., 2014. Unmanned aerial systems for photogrammetry and remote sensing: A review. ISPRS Journal of photogrammetry and remote sensing, 92, 79-97.

Edemsky, D., Popov, A., Prokopovich, I., \& Garbatsevich, V., 2021. Airborne Ground Penetrating Radar, Field Test. Remote Sensing, 13(4), 667.

Eeckhout, P., 1999. Pachacamac durant l'Intermédiaire récent: étude d'un site monumental préhispanique de la Côte centrale du Pérou. British Archaeological Reports International Series, 747.

Eeckhout, P., 2013. Change and permanency on the coast of ancient Peru: the religious site of Pachacamac. World archaeology, 45(1), 137-160.

Elkhrachy, I., 2019. Modeling and visualization of three dimensional objects using low-cost terrestrial photogrammetry. International Journal of Architectural Heritage.

Feng, C., Yu, D., Liang, Y., Guo, D., Wang, Q., \& Cui, X., 2019. ASSESSMENT OF INFLUENCE OF IMAGE PROCESSING ON FULLY AUTOMATIC UAV PHOTOGRAMMETRY. International Archives of the Photogrammetry, Remote Sensing \& Spatial Information Sciences.

Hill, A. C., Laugier, E. J., \& Casana, J., 2020. Archaeological remote sensing using multi-temporal, drone-acquired thermal and Near Infrared (NIR) Imagery: A case study at the Enfield Shaker Village, New Hampshire. Remote Sensing, 12(4), 690.

Lo Buglio, D., Lardinois, V. and De Luca, L., 2015. 'What do thirty-one columns say about a "theoretical" thirty-second?', Journal on Computing and Cultural Heritage (JOCCH), 8(1), pp. $1-18$.

Makowski, K., \& Vallenas, A., 2015. La ocupación lima en el valle de Lurín: en los orígenes de Pachacamac monumental. Boletín de arqueología PUCP, (19), 97-143.

Malfitana, D., Leucci, G., Fragalà, G., Masini, N., Scardozzi, G., Cacciaguerra, G., Santagati, C., \& Shehi, E., 2015. The potential of integrated GPR survey and aerial photographic analysis of historic urban areas: A case study and digital reconstruction of a Late Roman villa in Durrës (Albania). Journal of Archaeological Science: Reports, 4, 276-284.

Marín-Buzón, C., Pérez-Romero, A., López-Castro, J. L., Ben Jerbania, I., \& Manzano-Agugliaro, F., 2021. Photogrammetry as a New Scientific Tool in Archaeology: Worldwide Research Trends. Sustainability, 13(9), 5319. 
Mozas-Calvache, A. T., Pérez-García, J. L., Cardenal-Escarcena, F. J., Mata-Castro, E., \& Delgado-García, J., 2012. Method for photogrammetric surveying of archaeological sites with light aerial platforms. Journal of Archaeological Science, 39(2), 521530 .

Neubauer, W., Eder-Hinterleitner, A., Seren, S., \& Melichar, P., 2002. Georadar in the Roman civil town Carnuntum, Austria: An approach for archaeological interpretation of GPR data. Archaeological prospection, 9(3), 135-156.

Piga, C., Piroddi, L., Pompianu, E., Ranieri, G., Stocco, S., \& Trogu, A., 2014. Integrated geophysical and aerial sensing methods for archaeology: a case history in the Punic Site of Villamar (Sardinia, Italy). Remote Sensing, 6(11), 10986-11012.

Pisz, M., Tomas, A., \& Hegyi, A., 2020. Non-destructive research in the surroundings of the Roman Fort Tibiscum (today Romania). Archaeological Prospection, 27(3), 219-238.

Poirier, N., Hautefeuille, F., \& Calastrenc, C., 2013. Low altitude thermal survey by means of an automated unmanned aerial vehicle for the detection of archaeological buried structures. Archaeological Prospection, 20(4), 303-307.

Pozzi-Escot, D., Oshiro, J., Romano, G., Capozzoli, L., Lasaponara, R., \& Masini, N., 2018. Traces in the desert: use of new technologies for the study and valorization of the Pachacamac sanctuary-Lima, Peru. Heritage Science, 6(1), 112.

Rami, A. R., 2012. Photogrammetry for archaeological documentation and cultural heritage conservation. Special applications of photogrammetry, 97.

Sabina, J. Á. R., Valle, D. G., Ruiz, C. P., García, J. M. M., \& Laguna, A. G., 2015. Aerial Photogrammetry by drone in archaeological sites with large structures. Methodological approach and practical application in the medieval castles of Campo de Montiel. Virtual Archaeology Review, 6(13), 5-19.

Saleri, R., Cappellini, V., Nony, N., De Luca, L., PierrotDeseilligny, M., Bardiere, E., \& Campi, M., 2013. UAV photogrammetry for archaeological survey: The Theaters area of Pompeii. In 2013 Digital heritage international congress (DigitalHeritage) (Vol. 2, pp. 497-502). IEEE.

Sebar, L. E., Grassini, S., Parvis, M., \& Lombardo, L., 2021. A low-cost automatic acquisition system for photogrammetry. In 2021 IEEE International Instrumentation and Measurement Technology Conference (I2MTC) (pp. 1-6). IEEE.

Thomas, H., 2018. Some like it hot: The impact of next generation FLIR Systems thermal cameras on archaeological thermography. Archaeological Prospection, 25(1), 81-87.

Van Dongen, A., Lambot, S., Eeckhout, P., \& Buglio, D. L., 2018. UAV-based modeling to see the non-visible: A methodological reflection in Pachacamac. In 2018 3rd Digital Heritage International Congress (DigitalHERITAGE) held jointly with 2018 24th International Conference on Virtual Systems \& Multimedia (VSMM 2018) (pp. 1-4). IEEE.

Verdonck, L., 2008. Using the three-dimensional capabilities of GPR to reinterpret the Roman town of Mariana (Corsica). Proceedings of the 36th CAA Conference, 2, 6.
Wierzbicki, D., 2018. Multi-camera imaging system for UAV photogrammetry. Sensors, 18(8), 2433.

Wu, K., Rodriguez, G. A., Zajc, M., Jacquemin, E., Clément, M., De Coster, A., \& Lambot, S., 2019. A new drone-borne GPR for soil moisture mapping. Remote Sensing of Environment, 235, 111456. 